\title{
Construction of a Teaching Package on Promoting Prosocial Internet Use and Preventing Antisocial Internet Use
}

\author{
Hing Keung Ma, Miranda K. Y. Chu, and Winnie W. Y. Chan \\ Department of Education Studies, Hong Kong Baptist University, Hong Kong
}

Received 15 March 2011; Revised 30 July 2011; Accepted 16 August 2011

Academic Editor: Joav Merrick

\begin{abstract}
In the construction of the teaching package on the Internet use, two major moral characters, respect and responsibility, form the core theoretical basis. The respect character consists of respect for others and self-respect while the responsibility character contains social, civil, and global responsibility. There are a total of nine units on the Internet use in the junior secondary curriculum. There are two units in Secondary One curriculum: the first unit deals with cheating behavior and privacy issues concerning the Internet, and the second one discusses the effect of excessive use of the Internet on life and study. In Secondary Two curriculum, we discuss the following social phenomena on the Internet with students: online shopping, pornographic materials on internet, and infringement of a copyright. Finally, we have designed four units on the Internet use in Secondary Three curriculum which focuses more on the relationship between the Internet use and our health. We try to answer the question on how we can use the Internet healthily and also the possibility on how it may hurt us. Similar to the second unit in Secondary One curriculum, we have designed three more units on discussing the effects of excessive use of the Internet with students. We would like to alert students that ineffective use of the Internet will hurt us mentally and physically. For illustrative purposes, two units in the Secondary One and Two curriculums are outlined in this paper.
\end{abstract}

KEYWORDS: Teaching package, prosocial Internet use, antisocial Internet use 


\section{INTRODUCTION}

According to various surveys $[1,2]$, about two-thirds of the population are Internet users. More importantly, a substantial proportion of the Internet users (ranging from $4.0 \%$ to 20\%) [3-7], could be regarded as Internet addicts. The characteristics of these Internet addicts include the following: (1) excessive use of the Internet, (2) obsessive thought about the Internet, (3) pleasant feeling in Internet use, (4) tolerance, (5) diminished impulse control, (6) withdrawal, (7) negative impact on life, (8) poor parental and family interactions, (9) less friends and romantic relationships, (10) health problems, (11) lower academic performance, and (12) lonely character (details are given in [8]). One of the objectives of the construction of the new P.A.T.H.S. teaching package is to discuss with students the characteristics of Internet addicts and also the strategies to prevent themselves from becoming Internet addicts.

As more and more people are using Internet every day, the positive and negative use of the Internet becomes a prevalent and eminent issue in school education. We classify the Internet uses into three major categories.

\subsection{Three Types of Internet Behavior}

There are three major types of Internet behaviors: (1) prosocial internet behavior: it includes helping behavior, cooperation and sharing, and maintaining affective relationships and normative behaviors. For example, people using the Internet to teach and learn, to conduct community and voluntary work, and to set up discussion platforms for political activities such as supporting or criticizing governmental policies. (2) Common or usual internet behavior: it refers to the use of the Internet in a neutral and nonmoral basis. For example, using the Internet for communication or for entertainment. (3) Antisocial internet behavior: it includes antisocial, illegal or aggressive behaviors such as illegal downloading, selling or purchasing fake goods, cheating, cyber-bullying, illegal online gambling, or obtaining pornographic or aggressive information (details are given in [8]).

\subsection{Gender and Cultural Consideration in Internet Use}

People usually think that girls are more prosocial and less antisocial than boys. However, research findings on the sex differences in prosocial behavior are not clear and consistent as it is commonly believed [9]. On the other hand, research findings support that boys are in general more antisocial than girls [10]. It is argued that the behavior of internet use is similar to daily life social behavior. In other words, behavior of Internet use is a kind of social behavior. Ma et al. [11] found that boys are more delinquent in internet use than girls. In addition, boys spent more time in Internet use weekly than girls. It is argued that Chinese people tend to have higher expectation in the educational achievement of boys than girls, and boys are often given more opportunity and resources than girls [12].

In a cross-cultural study of undergraduate students on the Internet use, Graff et al. [13] found that the behavioral attitude of the Chinese students was more favorable than their UK counterparts. They also found that Chinese students reported higher Internet usage than the UK students. In another study, Li and Kirkup [14] found that British students tended to use the computer for more study purposes than the Chinese students. On the other hand, Chinese students were more confident about their advanced computer skills than their British counterparts. In addition, they also found that the male students in both countries were also more confident about their computer skills than the female students.

In the new P.A.T.H.S. teaching package, a section on the Internet use was constructed. The objective of this paper is to spell out clearly the rationale, contents, and educational implications of the package construction. The package aims to promote positive Internet use and prevent antisocial Internet use. 


\section{POSITIVE CHARACTER AND INTERNET BEHAVIOUR}

Ma [15] proposed a set of primary moral or positive characters that we need to help children and adolescents to develop. These moral or positive characters are (1) humanity, (2) intelligence, (3) courage, (4) conscience, (5) autonomy, (6) respect, (7) responsibility, (8) naturalness, (9) loyalty, and (10) humility. According to Lickona [16], respect and responsibility are two major characters that schools should teach. These two characters are particularly relevant to our discussion and hence would be elaborated in detail here.

\section{RESPECT}

Respect "takes three major forms: respect of oneself, respect for other people, and respect for all forms of life and the environment that sustains them" [16, page 43]. Similarly, Maslow [17] regarded esteem needs as one of the major basic needs in his Hierarchy of Basic Needs.

\subsection{Self-Respect}

One of the major characteristics of Internet addicts is low self-esteem, lack of confidence-these people tend to withdraw when they face challenges. In addition, they are less able to control their emotions especially in stressful situations.

When people have self-esteem, they tend to be less dependent on other's approval. They are then more autonomous and self-reliant. Unless you have respect for your own self, it would be difficult for you to have respect for others [16, pages 58-59]. The development of positive self-esteem and self-confidence is perhaps one of the best ways to get away from undesirable activities such as Internet addiction. The development of personal autonomy and self-discipline, self-regulation, or self-control contributes to the development of positive self-esteem.

\subsection{Respect for Others}

One way to respect others is to respect discipline, group rules, social law, and other's basic rights. People who carry out antisocial or delinquent activities online (e.g., downloading file and music without permission, bullying other people, cheating others, illegal gambling, etc.) do not respect others or do not intend to abide by the law.

Respecting others includes an affective concern for other's welfare and rights. People tend to respect others in a group if they have a clear and affirmed group identity. Similarly people love their country and people of their own country if they have a clear national identity. Ma [18, page 381] argued that "it is important to help adolescents in our society to achieve a clear and positive national and racial identity so that they can live happily with all people in their own country." The development of national identity and the respect for the social and political institutions is a major focus of education.

\subsection{Respect for the Environment That Sustains All Life}

Respect for all forms of life includes respect for animal rights and the rights of all living things. It also includes a respect and love of nature and hence will try one's best to protect nature. Respect for the environment that sustains all life is based on the extension of the Principles of Universal Justice and Principles of Universal Love to all living things [19, 20]. In other words, we should not only be fair to all people but also to all other living things; we should not only love all people but also love all the living things in the world. 


\section{RESPONSIBILITY}

Responsibility "includes taking care of one's self and others, fulfilling our obligations, contributing to our communities, alleviating suffering, and building a better world" [16, page 68]. The moral value of responsibility is derived from the value of respect. The value of responsibility is elaborated from four different perspectives.

\subsection{Personal Responsibility}

One's obligation and responsibility is based on one's self-chosen ethical principles. The ethical principles may include one's own moral values or universal ethical principles such as Principles of Universal Justice and Principles of Universal Love. Personal responsibility also refers to one's reliability and trustworthiness.

\subsection{Responsibility for Family Members}

The norm of filial piety, parenthood, sibling love, and spousal relationship prescribe people to be responsible and accountable for the welfare and protection of their parents, children, siblings, and spouse. People are more willing to sacrifice their personal interests for the benefits of their family members than other people such as friends, acquaintances, and strangers [21, 22].

\subsection{Social and Civil Responsibility}

Every citizen in our society has the obligation to perform certain duties "including the responsibility to obey the law, to pay one's taxes, to respect the rights of other people, to fight for one's country, and generally to fulfil one's social obligations" [23, page 2]. The responsibility to obey the law and the obligations to respect the rights of other people are closely related to Internet activities of the adolescents nowadays and will therefore be discussed in more detail.

People should abide by the law in their daily behaviour which include Internet activities. For example, they should not (a) bully others online, (b) download film or music without permission, (c) gamble illegally online, (d) steal others' properties online, and (e) selling and purchasing fake goods online.

Everyone in every society has some basic rights which must be upheld and protected regardless of the opinion of the majority of people. These basic rights are regarded as universal in the sense that every person in every society should have a just or fair claim of these rights. The contents of these basic rights have been elaborated in detail by Kohlberg and his associates: "All citizens have rights to (1) freedom from arbitrary punishment, (2) property, (3) freedom to enter into affiliative or family contracts and relations, (4) fair exercise of authority and political rights to have a say in the government, (5) moral respect or dignity, (6) legal justice, (7) freedom to make contractual agreements, (8) access to information, (9) certain civil rights, and (10) a right to life." [24, pages 53-54]. The antisocial Internet activities are usually related to the infringement of some of the basic rights. Two major examples are as follows. (a) Cyber-bullying: bullying others online sometimes involves punishing others aggressively and arbitrarily, and therefore is infringing one's rights to freedom from arbitrary punishment and the rights to moral respect or dignity. (b) Downloading film and music without permission or selling fake goods online is definitely infringing other's rights to intellectual property.

\subsection{Global Responsibility}

As a world citizen, one has responsibility to take care of the welfare of the people in his/her own country and also people in other countries. Internet in some sense shortens the time and "distance" for people to 
communicate and interact with people all over the world. The concept of global responsibility and world citizenship is crucial to Internet behaviours. One has the responsibility to observe not only the law in one's own country but also the international law. One should also respect the rights and traditional values of people in other cultures. In general, one should defend the universal justice for all people in the world. Finally, global responsibility can also be extended to all living things in the world, and we should defend universal justice and exhibit universal love to all living things in the world.

\section{THE RELATION OF POSITIVE YOUTH DEVELOPMENT CONSTRUCTS TO RESPECT AND RESPONSIBILITY CONSTRUCTS}

The original P.A.T.H.S. program was constructed based on Catalano et al.'s [25] 15 positive youth development constructs, which cover the major aspects of youth development. A detailed discussion on the application of Catalano's constructs in the development of the P.A.T.H.S. program could be found in Shek et al. [26]. The 15 constructs will be divided into three groups.

\subsection{Social Skills and Abilities}

These social skill and ability constructs include cognitive competence, emotional competence, behavioral competence, social competence, and moral competence. These social skills are essential operational and behavioral skills for the constructs of respect and responsibility. They are the social and emotional intelligence that one needs to develop in order to realize the constructs of respect and responsibility in a social situation.

\subsection{Self-Concept and Self-Management}

These constructs place emphasis on self-concept and individuality. They include self-determination, selfefficacy, spirituality, clear and positive identity, and beliefs in the future. This group of constructs is closely related to the Self-respect and Respect for others. In other words, the development of esteem needs (a need for self-respect and respect from others) is positively associated with the development of this group of positive youth constructs.

\subsection{Social Value and Social Relationships}

These constructs put more emphasis on morality, social value, and group discipline. They include prosocial involvement, fostering prosocial norms, promotion of bonding, resilience, and recognition for positive behavior. This group of positive youth constructs is positively related to social and civil responsibility (including family responsibility) and global responsibility. The development of social responsibility ties with the development of the social-oriented positive youth constructs.

The relation between Catalano's positive youth constructs and the constructs of respect and responsibility is outlined in Figure 1. The different types of Internet behaviors in our teaching kit are also included in Table 1. It is argued that low esteem and low responsibility are associated with antisocial Internet behavior. On the other hand, high esteem and high responsibility are associated with prosocial or positive Internet behavior. The educational implications of the Internet Use Program are presented in Figure 2. 


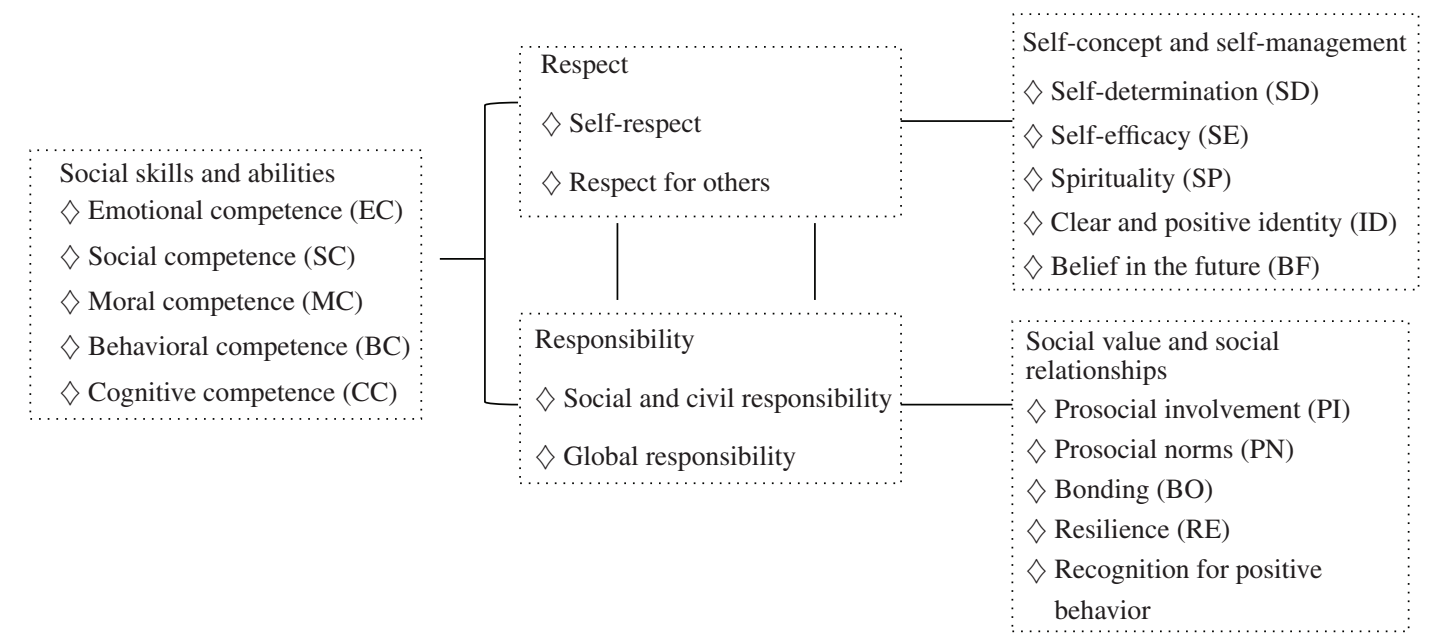

FIGURE 1: The relation of positive youth development constructs to respect and responsibility.

\section{A TEACHING PACKAGE ON INTERNET USE}

There are nine units on the Internet use in the Secondary One to Secondary Three curriculums. These units are concerned about the different areas of the Internet use such as current development of ICT, relationship between social life and the Internet, legal issues in Internet use, and the strategies of using ICT healthily.

There are two units in Secondary one curriculum: the first unit deals with cheating behavior and privacy issues in the Internet and the second one discusses the effect of excessive use of the Internet on life and study. In Secondary Two curriculum, we discuss the following social phenomenon in the Internet with students: online shopping, pornographic materials on internet and infringement of a copyright. Finally, we have designed four units on the Internet use in Secondary Three curriculum. We will focus more on the relationship between Internet use and our health. We try to answer the question on how we can use the Internet healthily and also the possibility on how it may hurt us. Similar to the second unit in Secondary One curriculum, we have designed three more units on discussing the effects of excessive use of the Internet with students. We would like to alert students that ineffective use of Internet will hurt us mentally and physically. Many students like to play computer games on the Internet, and undoubtedly, some of them are aggressive games. What is the effect of playing aggressive online games on their social behavior? We have designed a unit to discuss this issue intensively with the students. For illustrative purpose, one unit in the Secondary One (Unit IT1.1) and one in the Two (Unit IT2.3) curriculum are outlined in the following section. The learning targets, classroom activities and values in action, and expected learning outcomes are discussed in detail.

\subsection{Unit IT 1.1: "Lying or Not"}

\subsubsection{Learning Targets}

(1) To understand that lying online is irresponsible and disrespectful, and (2) to learn to respect privacy. Unit IT 1.1 focuses on the relationship between social life and the Internet. This unit aims at helping students to learn to be respectful and responsible when using the Internet.

\subsubsection{Classroom Activities and Value in Action}

A number of hypothetical scenarios involving using MSN were constructed. In one scenario, "You have made a friend online recently, and you want to spend time with him/her in a karaoke restaurant on the 
TABLE 1: P.A.T.H.S. program: Internet use teaching kit (S1-S3).

\begin{tabular}{|c|c|c|c|}
\hline Grade & $\begin{array}{l}\text { Unit } \\
\text { code }\end{array}$ & Unit & Unit aims \\
\hline \multirow{3}{*}{$\mathrm{S} 1$} & IT 1.1 & $\begin{array}{l}\text { Lying or not } \\
\text { (30 minutes) }\end{array}$ & $\begin{array}{l}\text { To learn to be respectful and } \\
\text { responsible when using the Internet }\end{array}$ \\
\hline & & & \\
\hline & IT 1.2 & $\begin{array}{l}\text { Smart user } \\
(30 \text { minutes })\end{array}$ & $\begin{array}{l}\text { To learn how to use the Internet with } \\
\text { self-control to prevent it from } \\
\text { interrupting our daily life }\end{array}$ \\
\hline & IT 2.1 & $\begin{array}{l}\text { Watch out } \\
\text { (30 minutes) }\end{array}$ & $\begin{array}{l}\text { To learn about the potential traps on } \\
\text { the internet that students should } \\
\text { know how to protect themselves and } \\
\text { handle the issue carefully. }\end{array}$ \\
\hline $\mathrm{S} 2$ & IT 2.2 & $\begin{array}{l}\text { Sex-surfing } \\
(30 \text { minutes })\end{array}$ & $\begin{array}{l}\text { To cultivate right attitude towards } \\
\text { searching sex-related information on } \\
\text { the internet }\end{array}$ \\
\hline
\end{tabular}

Learning targets

(i) To understand that lying online is irresponsible and disrespectful

(ii) To learn to respect privacy

(i) To understand how excessive Internet activities would affect daily life and interpersonal relationships

(ii) To understand that we have other activities apart from surfing the internet, and we should know how to make choices

(i) To surf the websites and handle the information carefully

(ii) To be self-protective against loss from all online trading

To learn not to totally trust the sex-related information offered on the net, as well as to learn how to distinguish between the right and the wrong information

(i) To understand that infringement of a copyright is unethical

(ii) To understand the consequences of illegal Internet use

IT 3.1 Unresolved To enhance self-reflection on using

(i) To understand how to solve problems

(ii) To enhance self-reflection on using Internet is a good way or not to solve personal problems in daily life

(i) To understand the features of over-using

IT 3.2 Getting To look into the impacts of devoting minutes) oneself to the Internet world and reflect on one's habit of surfing the Internet the Internet and do self-evaluation

(ii) To understand that the impacts of devoting oneself to the Internet world and think of some ways to improve

(i) To learn not to indulge in violent and virtual reality computer games

(ii) To know how to distinguish the virtual world and reality

(i) To understand that prolonged use of high technological products have impact on our health

(ii) To learn to use high technological products correctly to avoid affecting health

coming Sunday." The online friend asked you to tell him/her something about yourself. Would you tell the truth, or would you try to hide your real appearance and background?

Through discussing the scenario of using MSN, students are expected to understand that one should be responsible for his/her every word and deed online and to learn to put one into the shoes of others so as 


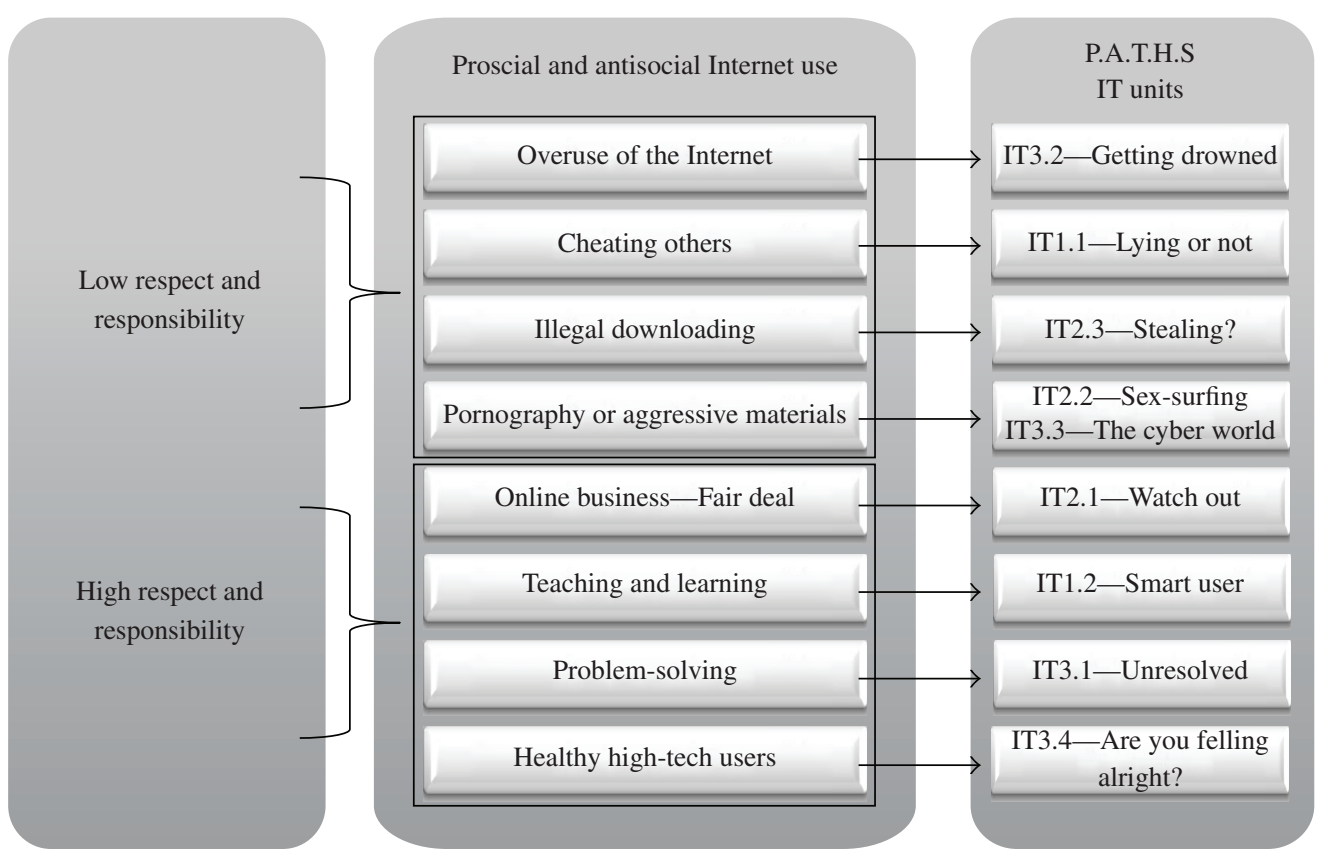

FIGURE 2: Educational implications of the Internet Use Program.

to avoid hurting others. Students may experience how people lie and how they are deceived on the Internet. It leads them to reflect and judge whether such behavior could be considered as acceptable and regular in society. In order to explain the reliability of online information, instructors may collect some of the latest news clippings which can well describe fraudulent Internet friends.

In addition, respecting privacy is another important learning target of this unit. There is a growing trend that teenagers like to film in public areas with their mobile phone cameras and then share the photos on the internet. Such behavior is rude and inconsiderate. Based on this phenomenon, we have designed a scenario in which the main character films a male senior physically harassing a female schoolmate while holding a cigarette (possibly with a drug inside) in the bully's hand. Students are asked to make decisions for the character in the scenario, whether he/she should film the incident and share the video on the Internet or not. Respecting privacy and activities of others is important. Since this kind of behavior may contravene some laws, instructors are reminded to understand the relevant laws before teaching so that they can explain in more detail during the lesson.

\subsubsection{Expected Outcomes}

After this session, students are expected to understand more that they should be respectful and responsible in the online world. They will have the social ability to develop positive relationships of mutual support with different people in daily life, as well as on the Internet.

\subsection{IT 2.3: "Stealing"}

\subsubsection{Learning Targets}

To understand that infringement of a copyright is unethical, and To understand the consequences of illegal Internet use. 


\subsubsection{Classroom Activities and Values in Action}

The main focus of this unit is to enhance students' knowledge of proper Internet use by illustrating that infringement of a copyright is unethical and irresponsible. Prosocial norm is being highlighted in this unit so as to promote proper and positive Internet use in this unit.

In the warm-up activity, we intend to let students reflect on the wide use of illegal software nowadays. The Internet is not another world and we should not think that our identity is fully protected. All actions on the Internet can be traced.

Two video clips would be introduced in our primary activity: (1) "Sing and his two classmates want to watch a new movie, which is just in stock in a DVD shop. It costs $\$ 25$. However, this movie can be downloaded from the Internet. His classmate wants to download this movie online, but Sing thinks this is wrong." (2) In doing English comprehension homework with your best friend, you discover that she is plagiarizing online articles, and you think she should not do that. These two video clips portray daily illegal phenomena of Internet use: illegal downloading of Internet materials and Internet plagiarism. This is a right time to let students reflect on their daily behavior when using the Internet materials. Students can further understand that Internet plagiarism is unlawful, and they should learn to respect copyrights.

In another activity, we would like to show the students that one of the most common phenomena in the Internet is forwarding some email files or photos (e.g., naked photos of artists) to others without permission. We would explain in detail that uploading or transmitting obscene or indecent articles to persons under 18 is illegal. We need to be responsible for our behavior. The photo owners may also be sued by concerned parties through civil proceedings. An appendix of "The Control of Obscene and Indecent Articles Ordinance" is also attached for students as a reference.

It is common for students to think that as long as they are careful, no one will know or charge them on illegal Internet use. We pinpoint that this is a wrong belief and that we all have to take responsibility for our actions and Internet identity and that activities are traceable and that the police can efficiently trace illegal Internet behavior.

\subsubsection{Expected Outcomes}

Students are expected to learn the legal and ethical perspectives on infringement of a copyright in the Internet and they are also expected to develop a positive and moral attitude in respecting the rights for intellectual properties on the Internet.

A summary of the nine units on Internet Use Program units is already given in Table 1.

\section{CONCLUSIVE REMARKS}

While the current teaching package has dealt with some important issues in Internet use, there are still a lot of meaningful issues to be included in the future teaching package. For examples, what are the major differences between the cyber world and real world? To what extent is the cyber world virtual? How to promote prosocial Internet use and prevent antisocial Internet use? Does the Internet bring more benefits to human beings?

In addition, the Internet can be used as a platform for teaching and learning. The information and communication technology nowadays would provide an interesting, interactive, and effective channel for teaching and learning in most of the subjects including liberal studies and life and ethics education.

\section{ACKNOWLEDGMENT}

This paper was supported by the Hong Kong Jockey Club Charities Trust. 


\section{REFERENCES}

[1] Internet World Stats, "Hong Kong: Internet Usage Stats and MarketReport,” 2010, http://www.internetworldstats .com/asia/hk.htm.

[2] Hong Kong Internet Project, "Internet use in Hong Kong: The 2008 annual survey report," Web Mining Lab, Dept of Media \& Communication, City University of Hong Kong, 2009, http://newmedia.cityu.edu.hk/hkip .

[3] D. T. L. Shek, V. M. Y. Tang, and C. Y. Lo, "Internet addiction in Chinese adolescents in Hong Kong: assessment, profiles, and psychosocial correlates," TheScientificWorldJournal, vol. 8, pp. 776-787, 2008.

[4] K. W. Fu, W. S. C. Chan, P. W. C. Wong, and P. S. F. Yip, "Internet addiction: p revalence, discriminant validity and correlates among adolescents in Hong Kong," British Journal of Psychiatry, vol. 196, no. 6, pp. 486-492, 2010.

[5] S. S. J. Lin and C.-C. Tsai, "Sensation seeking and internet dependence of Taiwanese high school adolescents," Computers in Human Behavior, vol. 18, no. 4, pp. 411-426, 2002.

[6] J. Morahan-Martin and P. Schumacher, "Incidence and correlates of pathological internet use among college students," Computers in Human Behavior, vol. 16, no. 1, pp. 13-29, 2000.

[7] W. Wang, "Internet dependency and psychosocial maturity among college students," International Journal of Human Computer Studies, vol. 55, no. 6, pp. 919-938, 2001.

[8] H. K. Ma, Prosocial and Antisocial Internet Use of Adolescents: Theory, Research and Current Issues, Hung Kong Baptist University. In press.

[9] N. Eisenberg and R. A. Fabes, "Prosocial development," in Handbook of Child Psychology, W. Damon and N. Eisenberg, Eds., vol. 3, pp. 701-778, John Wiley \& Sons, New York, NY, USA, 5th edition, 1998.

[10] J. D. Coie and K. A. Dodge, "Aggression and antisocial behavior," in Handbook of Child Psychology, W. Damon and N. Eisenberg, Eds., vol. 3, pp. 779-862, John Wiley \& Sons, New York, NY, USA, 5th edition, 1998.

[11] H. K. Ma, S. S. C. Li, and J. W. C. Pow, "The relation of Internet use to prosocial and antisocial behavior in Chinese adolescents," Cyberpsychology,Behavior, and Social Networking, vol. 14, no. 3, pp. 123-130, 2011.

[12] F. M. Cheung, "Gender role development," in Growing Upthe Chinese Way: Chinese Child and Adolescent Development, S. Lau, Ed., pp. 44-67, The Chinese University Press, Hong Kong, 1996.

[13] M. Graff, J. Davies, and M. McNorton, "Cognitive style andcross-cultural differences in Internet use and computer attitudes," 2004, http://www.eurodl.org/materials/contrib/2004/Graff_Davies_McNorton.html .

[14] N. Li and G. Kirkup, "Gender and cultural differences in Internet use: a study of China and the UK," Computers and Education, vol. 48, no. 2, pp. 301-317, 2007.

[15] H. K. Ma, "Moral development and moral education: an integrated approach ," Educational Research Journal, vol. 24, no. 2, pp. 293-326, 2009.

[16] T. Lickona, Education for Character: How Our Schools Can Teach Respect and Responsibility, Bantam Books, New York, NY, USA, 1991.

[17] A. H. Maslow, Motivation and Personality, Harper \& Row, New York, NY, USA, 3rd edition, 1987.

[18] H. K. Ma, "Social competence as a positive youth development construct: conceptual bases and implications for curriculum development," International Journal of Adolescent Medicine and Health, vol. 18, no. 3, pp. 379-385, 2006.

[19] H. K. Ma, "The moral judgment development of the Chinese people: a theoretical model," Philosophica, vol. 49, pp. 55-82, 1992.

[20] H. K. Ma, "The affective and cognitive aspects of moral development of he Chinese people: a seven stage development theory," Indigenous Psychological Research in Chinese Societies, vol. 7, pp. 166-212, 1997 (Chinese).

[21] H. K. Ma, "Moral orientation and moral judgment in adolescents: Hong Kong, Mainland China, and England," Journal of Cross-Cultural Psychology, vol. 20, pp. 152-177, 1989.

[22] H. K. Ma, "The relation of altruistic orientation to human relationships and moral judgment in Chinese people," International Journal of Psychology, vol. 27, pp. 377-400, 1992.

[23] J. J. Cogan, "Citizenship education for the 21st century: setting the context," in Citizenship for the 21 st Century: An International Perspective on Education, J. J. Cogan and R. Derricott, Eds., pp. 1-20, Kogan Page, London, UK, 1998. 
[24] A. Colby, J. Gibbs, L. Kohlberg, B. Speicher-Dubin, and D. Candee, "Standard Form Scoring Manual: Parts I-IV," Unpublished manuscript, Harvard University, 1979.

[25] R. F. Catalano, M. L. Berglund, J. A. M. Ryan, H. S. Lonczak, and J. D. Hawkins, "Positive youthdevelopment in the United States: research findings on evaluations of positiveyouth development programs," Prevention \& Treatment, vol. 5, no. 15, 2002.

[26] D. T. L. Shek, H. K. Ma, and J. Merrick, Positive Youth Development: Development of a Pioneering Program in a Chinese Context, Freund Publishing House, London, UK, 2007.

\section{This article should be cited as follows:}

Hing Keung Ma, Miranda K. Y. Chu, and Winnie W. Y. Chan, "Construction of a Teaching Package on Promoting Prosocial Internet Use and Preventing Antisocial Internet Use," TheScientificWorldJOURNAL, vol. 11, pp. 2136-2146, 2011. 